\title{
A Critical Evaluation of the Nonparametric Approach to Estimate Terrestrial Evaporation
}

\author{
Yongmin Yang, ${ }^{1,2}$ Hongbo $\mathrm{Su}^{3}{ }^{3}$ and Jianwei $\mathrm{Qi}^{4}$ \\ ${ }^{1}$ State Key Laboratory of Simulation and Regulation of Water Cycle in River Basin, Beijing 100038, China \\ ${ }^{2}$ Research Center on Flood and Drought Disaster Reduction of the Ministry of Water Resources, \\ China Institute of Water Resources and Hydropower Research, Beijing 100038, China \\ ${ }^{3}$ Department of Civil, Environmental and Geomatic Engineering, Florida Atlantic University, Boca Raton, FL 33431, USA \\ ${ }^{4}$ China Aero Geophysics Survey and Remote Sensing Center for Land and Resources, Beijing 100083, China
}

Correspondence should be addressed to Hongbo Su; hongbo@ieee.org

Received 7 April 2015; Accepted 13 May 2015

Academic Editor: Marcos Heil Costa

Copyright (C) 2016 Yongmin Yang et al. This is an open access article distributed under the Creative Commons Attribution License, which permits unrestricted use, distribution, and reproduction in any medium, provided the original work is properly cited.

Evapotranspiration (ET) estimation has been one of the most challenging problems in recent decades for hydrometeorologists. In this study, a nonparametric approach to estimate terrestrial evaporation was evaluated using both model simulation and measurements from three sites. Both the model simulation and the in situ evaluation at the Tiger Bush Site revealed that this approach would greatly overestimate ET under dry conditions (evaporative fraction smaller than 0.4). For the evaluation at the Tiger Bush Site, the difference between ET estimates and site observations could be as large as $130 \mathrm{~W} / \mathrm{m}^{2}$. However, this approach provided good estimates over the two crop sites. The Nash-Sutcliffe coefficient (E) was 0.9 and 0.94, respectively, for WC06 and Yingke. A further theoretical analysis indicates the nonparametric approach is very close to the equilibrium evaporation equation under wet conditions, and this can explain the good performance of this approach at the two crop sites in this study. The evaluation indicates that this approach needs more careful appraisal and that its application in dry conditions should be avoided.

\section{Introduction}

Water is fundamental to the coupled human-environment systems $[1,2]$. The role of the land surface in partitioning available water between evaporation and runoff and in partitioning available energy between sensible and latent heat fluxes is significant and affects the state of the atmosphere directly $[3,4]$. Evapotranspiration is a very important process that relates to energy and water exchange between the hydrosphere, atmosphere, and biosphere [5, 6]. Accurate estimate of ET will benefit water planning and management in arid and semiarid areas. Many methods have been proposed to measure ET at various scales [7]. Sap-flow and porometer readings are often used to measure ET from individual plants. The Bowen ratio and lysimeter and scintillometer readings are used to measure ET from fields. Eddy covariance (EC) and catchment water balance are often used to measure ET on a landscape scale. Remote sensing-based ET models are suitable for estimating ET on a regional scale.
Hydrometeorologists have striven for decades to estimate natural evaporation from land surfaces. Dalton [8] related evaporation to a wind function and vapor pressure deficit. Fick [9] proposed a one-dimensional form of diffusion equation, which greatly contributed to the understanding of evaporation. Bowen [10] presented the ratio of heat loss by conduction to that by evaporation (known as the Bowen ratio) as a function of vertical temperature and humidity gradients. Later, the Bowen ratio method is widely used for measuring ET. Penman [11] advanced the evaporation theory and proposed the combination method to estimate evaporation from an open water surface. Monteith [12] developed the Penman equation and extended it to cropped surfaces by introducing the surface and aerodynamic resistance. In the past few years, the FAO Penman-Monteith equation was recommended to estimate reference $\mathrm{ET}\left(\mathrm{ET}_{0}\right)$, and the "Kc-ET $\mathrm{ET}_{0}$ " approach has been widely used for computing crop water requirements [13]. Comprehensive reviews of the historical study of the natural evaporation from land can 
be found in numerous papers [3, 14, 15]. However, large discrepancies in latent and sensible heat fluxes were reported between field observations and general circulation model (GCM) simulations based on the above ET methods [16]. In the abovementioned methods, transfer coefficients such as surface resistance, conductance, or bulk coefficient are semiempirically or empirically parameterized and lead to different results and uncertainties in ET estimates [7, 17] because most of them could not be measured directly [15].

Recently, a nonparametric approach was proposed by Liu et al. [18] to estimate terrestrial evaporation. The nonparametric approach is derived from the thermodynamic process following Hamilton's principle. This approach requires measurements of air temperature, surface temperature, net radiation, and soil heat flux. The solution is simple and no parameterization of a transfer coefficient is needed. Liu et al. [18] evaluated this approach with observations from 26 eddy covariance sites, and they found that this approach showed a good performance at 23 sites. They further found that the nonparametric approach could achieve a compatible performance to the Penman-Monteith approach at two observation sites. However, careful appraisal is needed, and a more critical evaluation of the nonparametric approach is necessary. The purpose of this paper is to evaluate the capability of the nonparametric approach to predict ET at various soil moisture conditions. Section 2 presents a brief description of the nonparametric approach, the PenmanMonteith approach, and the Bowen ratio approach. Section 3 describes the datasets used in this study. Section 4 offers some insights into the nonparametric approach and compares the estimates with the site observations. Section 5 discusses issues related to the nonparametric approach, and Section 6 provides a conclusion.

\section{Methodology}

For a simple lumped system, when effects of unsteadiness, ice melt, photosynthesis, and advection can be neglected, the land surface energy balance equation can be written as [3]

$$
\left(R_{n}-G\right)=H+\mathrm{LE}
$$

where $R_{n}$ is the net radiation, $G$ is the soil heat flux, $H$ is the sensible heat flux, and LE is the latent heat flux; $\left(R_{n}-G\right)$ is often called the available energy. For one dimension, sensible and latent heat fluxes are described in terms of flux-gradient relationships [19]:

$$
\begin{aligned}
H & =\rho C_{p} \frac{T_{s}-T_{a}}{r_{a}}, \\
\mathrm{LE} & =\frac{\rho C_{p}}{\gamma} \frac{e_{s}^{*}-e_{a}}{r_{a}+r_{s}},
\end{aligned}
$$

where $\rho$ is the air density $\left(\mathrm{kg} / \mathrm{m}^{3}\right), C_{p}$ is the specific heat of air at constant pressure $\left(1,013 \mathrm{Jkg}^{-1{ }^{\circ}} \mathrm{C}^{-1}\right), \gamma$ is the psychrometric constant $\left(\mathrm{kPa}^{\circ} \mathrm{C}^{-1}\right), T_{s}$ and $T_{a}$ are the aerodynamic surface and air temperatures $\left({ }^{\circ} \mathrm{C}\right), e_{s}^{*}$ and $e_{a}$ are the water vapor pressure at the evaporating surface and in the air $(\mathrm{kPa})$, $r_{a}$ is the aerodynamic resistance $(\mathrm{s} / \mathrm{m})$, and $r_{s}$ is the surface resistance $(\mathrm{s} / \mathrm{m})$.

Bowen [10] expressed the Bowen ratio $(\beta)$ as

$$
\beta=\frac{H}{\mathrm{LE}} \text {. }
$$

The Bowen ratio can be determined from the profile data of water vapor pressure and air temperature:

$$
\beta=\gamma \frac{\Delta T}{\Delta e}
$$

where $\Delta T$ and $\Delta e$ are air temperature and water vapor pressure differences at two heights within the boundary layer. If the available energy is known, the combination of (1) and (4) produces

$$
\begin{aligned}
\mathrm{LE} & =\frac{\left(R_{n}-G\right)}{1+\beta}, \\
H & =\frac{\beta\left(R_{n}-G\right)}{1+\beta} .
\end{aligned}
$$

The Penman-Monteith equation [11, 12] eliminates the aerodynamic surface temperature and yields the following equation:

$$
\mathrm{LE}=\frac{\Delta\left(R_{n}-G\right)+\rho_{a} C_{p}\left(\left(e_{s}-e_{a}\right) / r_{a}\right)}{\Delta+\gamma\left(1+r_{s} / r_{a}\right)},
$$

where $\Delta$ is the slope of the saturation vapor pressure curve at air temperature $\left(\mathrm{kPa}^{\circ} \mathrm{C}^{-1}\right)$ and $e_{s}$ is the saturation water vapor pressure at air temperature $(\mathrm{kPa})$. The main feature of the Penman-Monteith equation is that it requires water vapor pressure, wind speed, and air temperature only at one level. All the parameters have been defined except for the surface resistance, which is to account for the evaporation deficit from unsaturated surfaces. Combining (1), (2), and (7), an expression for the aerodynamic surface temperature can be derived as follows [20]:

$$
T_{s}=T_{a}+\frac{\gamma\left(1+r_{s} / r_{a}\right)\left(r_{a} / \rho_{a} C_{p}\right)\left(R_{n}-G\right)-\left(e_{s}-e_{a}\right)}{\Delta+\gamma\left(1+r_{s} / r_{a}\right)} .
$$

This equation will be applied to the simulation analysis in the next section.

Liu et al. [18] proposed a nonparametric approach to estimate the actual ET. The derived equations are as follows:

$$
\begin{gathered}
\mathrm{LE}=\frac{\Delta}{\Delta+\gamma}\left(R_{n}-G\right)-\epsilon \sigma\left(T_{g}^{4}-T_{a}^{4}\right)+G \ln \left(\frac{T_{g}}{T_{a}}\right), \\
H=\frac{\gamma}{\Delta+\gamma}\left(R_{n}-G\right)+\epsilon \sigma\left(T_{g}^{4}-T_{a}^{4}\right)-G \ln \left(\frac{T_{g}}{T_{a}}\right),
\end{gathered}
$$

where $T_{g}$ is the ground surface temperature $(K)$, which is different from the aerodynamic surface temperature, $\epsilon$ is the surface emissivity, and $\sigma$ is the Stefan-Boltzmann constant. The latent and sensible heat fluxes are functions of air temperature, soil heat flux, and net radiation. More importantly, 
TABLE 1: Characteristics of the reference sites.

\begin{tabular}{lccccc}
\hline Site name & Country & Location & Köppen climate & Dominant land cover & ET observation systems \\
\hline WC06 & USA & $41.93 \mathrm{~N}, 93.75 \mathrm{~W}$ & Hot wet summer/cold wet winter & Cropland (corn) & Eddy covariance \\
Yingke & China & $38.85 \mathrm{~N}, 100.41 \mathrm{E}$ & Hot summer/cold winter/dry year-round & Cropland (corn) & Eddy covariance \\
$\begin{array}{l}\text { Tiger Bush } \\
\text { Site }\end{array}$ & Niger & $13.19 \mathrm{~N}, 2.24 \mathrm{E}$ & Hot and dry year-round & Bare soil & Bowen system \\
\hline
\end{tabular}

this approach is relatively simple and all the parameters are measureable. The derivation and more details of this approach can be found in the paper by Liu et al. [18]. There are three terms in (9) and (10) where the first term is generally called equilibrium evaporation (denominated as $E_{\text {eq }}$ in the following), the second term (in (10)) is denominated as $\mathrm{N}$ P_ST, and the third term (in (9)) is denominated as N-P_TT in the following.

\section{Data Description}

Three experiment datasets were collected to evaluate the nonparametric approach. Specifically, data from the SMACEX (Soil Moisture-Atmosphere Coupling Experiment; [21]), WATER (Watershed Allied Telemetry Experimental Research; [22]) and HAPEX-Sahel (Hydrological and Atmospheric Pilot Experiment in the Sahel; [23]) experiments were used in this study. Table 1 lists the characteristics of the reference sites.

3.1. SMACEX. The Soil Moisture-Atmosphere Coupling Experiment was conducted in Iowa, USA, from June 19 through July 9 in 2002 and was designed to provide multiscale dataset of vegetation, soil, and atmospheric states [21, 24]. The primary objectives were to extend microwave soil moisture observations and retrieval algorithms to changing crop biomass conditions and to provide validation data for the Advanced Microwave Scanning Radiometer (AMSR) brightness temperature and soil moisture retrieval algorithms. The land cover in Walnut Creek watershed is primarily composed of corn and soybean. Twelve field sites with eddy covariance (EC) were deployed in the center of the study area. There were 6 corn sites and 6 soybean sites.

The data used in this study were obtained from the WC06 site. The tower was instrumented with sensors for measuring turbulent fluxes of water vapor and sensible heat, as well as net radiation and soil heat flux at 30 min intervals. Additional hydrometeorological observations included wind speed and direction, air temperature, vapor pressure, nearsurface soil temperature, and moisture at $10 \mathrm{~min}$ intervals. In this study, the hydrometeorological data were resampled to $30 \mathrm{~min}$ to be compatible with heat flux measurements. Sensible and latent heat fluxes were adjusted by forcing the energy balance closure using the measured net solar radiation, soil heat flux, and Bowen ratio based on the approach suggested by Twine et al. [25]. The tower-based composite radiometric surface temperature was measured by Apogee infrared thermometers. Su et al. [24] corrected the data and applied them to evaluate the SEBS model. In this study, the correction method proposed by Su et al. [24] was employed.

3.2. WATER. The Watershed Allied Telemetry Experimental Research (WATER) is a simultaneous airborne, satelliteborne, and ground-based remote sensing experiment taking place in the Heihe River Basin, the second largest inland river basin in the arid regions of northwest China. The mission of this experiment was to improve the observability, understanding, and predictability of hydrological and related ecological processes at a catchment scale. A detailed introduction to WATER can be found at http://water.westgis.ac.cn/ or from the paper by Li et al. [22].

The observations from the Yingke station were collected in this study. The site is located in an oasis where the underlying cover is typical irrigated farmland. An Automatic Meteorological Station (AMS), a Soil Moisture and Temperature Measuring System (SMTMS), and an EC system were deployed at this site. Data from July 1 to July 15 in 2008 were collected in this study. Soil heat fluxes were estimated using the Thermal Diffusion Equation and Correction (TDEC) method proposed by Yang and Wang [26]. Surface temperature was estimated from the incoming and outgoing long-wave radiation measured with four component net radiometers. The surface emissivity was assumed to be 0.98 for the corn field. More detailed descriptions of the field observations can be found in the papers by Li et al. [22] and Song et al. [27].

3.3. HAPEX-Sahel. The HAPEX-Sahel experiment was undertaken in Niger, during 1991 and 1992. It aimed at improving the parameterization of land-surface-atmosphere interactions at the Global Circulation Model grid box scale [23]. Three supersites with detailed hydrometeorological studies were deployed in the $1^{\circ}$ square experimental domain.

In this study, the bare soil evaporation data collected from the Southern Supersite during the intensive observation period (IOP) in 1992 were used. The latent and sensible heat fluxes were measured with a Bowen ratio system that was very close to the soil surface $(0.05 \mathrm{~m}$ and $0.20 \mathrm{~m})$. The area was completely bare soil. The system also had a net radiometer and two soil heat plates deployed in the same place. The surface temperature was measured by infrared thermometers operating in the range of 8 to 14 micrometers. Air temperature, wet bulb temperature, wind speed, rainfall, incoming long-wave radiation, incoming shortwave radiation, and reflected solar radiation over bare soil were observed by an automatic weather station. Detailed information on this dataset can be found in the paper by Wallace and Holwill 


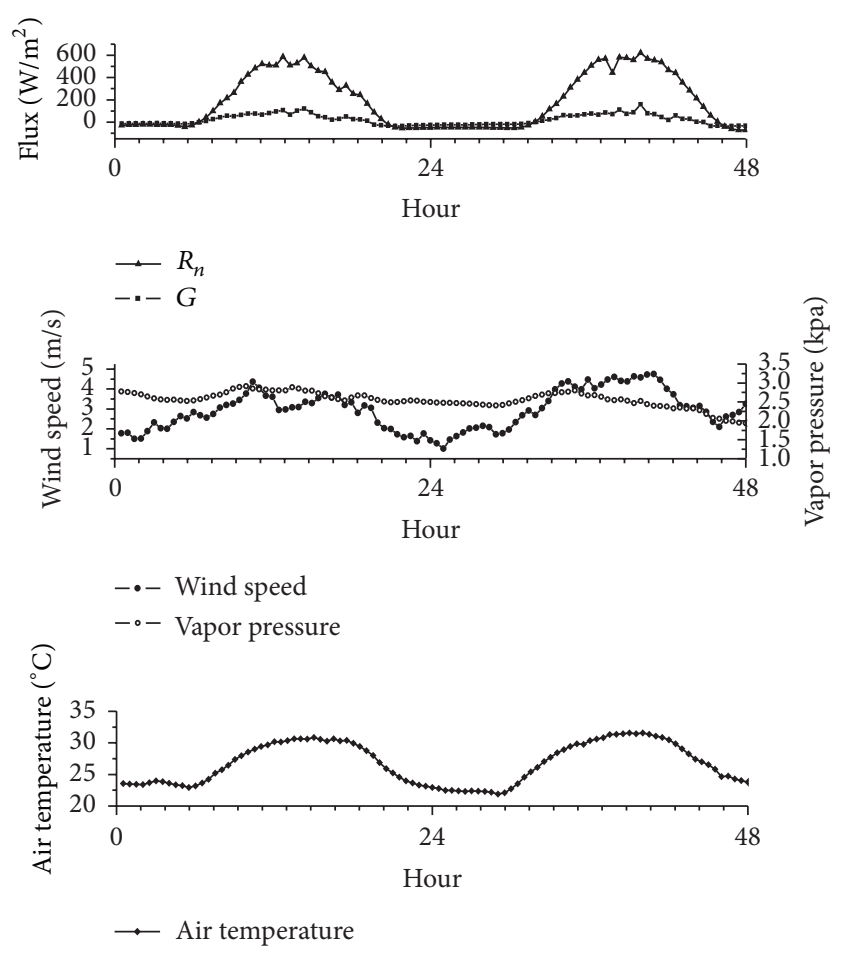

FIGURE 1: The diurnal variation of net radiation, soil heat flux, wind speed, vapor pressure, and air temperature for WC06 from DOY 172173.

[28]. The period from DOY 260 to 280 of 1992 was chosen in this study. During this time, there was no rainfall and it was the dry season in this area. The surface temperature was corrected with incoming long-wave radiation, and the bare soil emissivity was assumed to be 0.98 . The data were obtained from the HAPEX-Sahel information system (http://www.cesbio.ups-tlse.fr/hapex/).

\section{Results}

4.1. Simulation Analysis. Before the sites evaluation was undertaken, simulation analyses were carried out to compare the results derived from the nonparametric approach, the Penman-Monteith equation, and the Bowen ratio approach. Generally, two kinds of simulation were employed in this study. For the first one, the Penman-Monteith equation was compared with the nonparametric approach. To conduct this analysis, two days' (DOY 172 and 173) measurements from WC06 were selected. Figure 1 shows the diurnal variation of net radiation, soil heat flux, wind speed, vapor pressure, and air temperature for these two days. The observations included most parameters for the Penman-Monteith equation, except for surface resistance and aerodynamic resistance. To facilitate this analysis, the aerodynamic resistance was estimated using $r_{a}=208 / u$, where $u$ represents the wind speed in $\mathrm{m} / \mathrm{s}$ and $r_{a}$ is in $\mathrm{s} / \mathrm{m}$. This simple equation is often used to estimate the aerodynamic resistance for the reference grass surface [13]. The simulation process is as follows: at
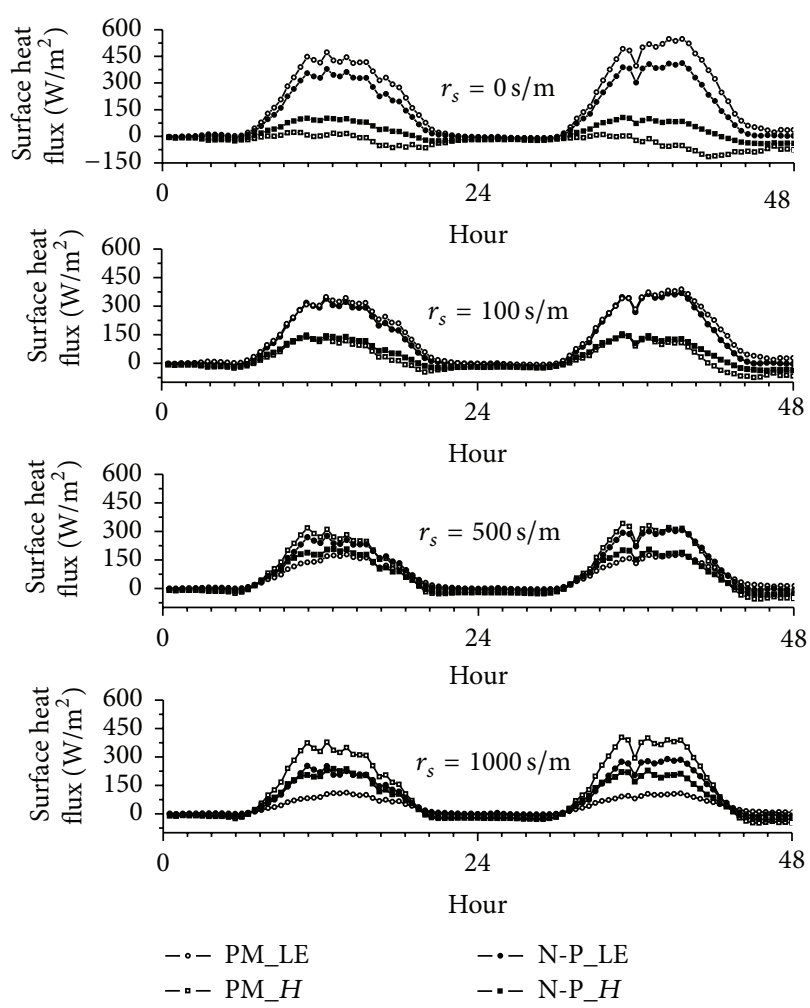

FIGURE 2: Comparison of surface heat fluxes derived from PenmanMonteith equation and the nonparametric approach.

first, the surface resistance was set as a constant value; then the latent and sensible heat fluxes can be estimated with the Penman-Monteith equation; subsequently, the aerodynamic surface temperature can be derived from (8); finally, assuming the ground surface temperature was equal to the aerodynamic surface temperature and the surface emissivity is equal to 0.98 , the latent and sensible heat fluxes can be estimated based on the nonparametric approach. It is worth noting that the aerodynamic surface temperature is actually different from the ground surface temperature. The difference between the aerodynamic surface temperature and the ground surface temperature is significant over the sparse vegetation area $[29,30]$. In this study, it was assumed that this simulation was carried out over dense grassland; therefore, the difference between the two can be neglected. Four scenario analyses were undertaken with the surface resistance set as $0,100,500$, and $1000 \mathrm{~s} / \mathrm{m}$, respectively. Figure 2 presents the comparison between the estimates from Penman-Monteith equation and the surface heat fluxes based on the nonparametric approach. For $r_{s}=0 \mathrm{~s} / \mathrm{m}$, which is for the dense grassland after a rainfall event, the grassland evaporates at the potential rate. The latent heat flux estimated by the Penman-Monteith equation is greater than the nonparametric approach. At the same time, the sensible heat flux estimated with Penman-Monteith is lower than the nonparametric approach. The largest difference between the estimates from the two approaches is about $100 \mathrm{~W} / \mathrm{m}^{2}$. For 
$r_{s}=100 \mathrm{~s} / \mathrm{m}$, this is generally the case for a well-irrigated grassland. The latent and sensible heat fluxes estimated with the two approaches show a good agreement. The surface heat fluxes estimated from two approaches are nearly equal under such conditions, for $r_{s}=500 \mathrm{~s} / \mathrm{m}$, which represents a water-stressed grassland. The latent heat flux estimated by the nonparametric approach is shown to be greater than that from the Penman-Monteith equation. The largest difference is about $120 \mathrm{~W} / \mathrm{m}^{2}$. On the contrary, the sensible heat flux based on the nonparametric approach is smaller than the PenmanMonteith-based estimates. For $r_{s}=1000 \mathrm{~s} / \mathrm{m}$, which stands for a grassland under a severe drought, the estimates of latent heat flux from the nonparametric approach are shown to be significantly greater than Penman-Monteith-based estimates. Meanwhile, the estimates of sensible heat flux from the nonparametric approach are shown to be much lower than the Penman-Monteith-based estimates. The difference of the latent heat flux derived from the two methods is as large as $160 \mathrm{~W} / \mathrm{m}^{2}$. The analyses above indicated the nonparametric approach and the Penman-Monteith equation may have great differences under dry circumstances. For the second one, the Bowen approach was compared with the nonparametric approach. The net radiation, air temperature, soil heat flux, and aerodynamic resistance need to be set at first. The values for net radiation, air temperature, and soil heat flux were set as $450 \mathrm{~W} / \mathrm{m}^{2}, 25^{\circ} \mathrm{C}$, and $135 \mathrm{~W} / \mathrm{m}^{2}$ based on the measurements at 11:00 am from the WC06 site. The aerodynamic resistance was set as $70 \mathrm{~s} / \mathrm{m}$, which is a typical value for grassland. Zhang et al. [31] pointed out that soil moisture availability and the Bowen ratio have a certain relationship. Under the same conditions of net radiation and soil heat flux, high soil moisture availability corresponds to a low Bowen ratio (see Figure 1 in their paper). Assuming the Bowen ratio ranged from 0 to 10 with the step of 0.2 , this may represent grasslands under different soil moisture conditions under the same radiation environment. The latent and sensible heat fluxes can be derived based on (6). Similar to the first simulation, the aerodynamic surface temperature was estimated using (8). It is still assumed that the aerodynamic surface temperature is an approximation to the ground surface temperature and the emissivity was set as 0.98 , and then the latent and sensible heat fluxes can be derived from the nonparametric approach. Figure 3 presents the comparison of latent heat flux and sensible heat flux derived from the Bowen ratio approach and the nonparametric approach. For a Bowen ratio smaller than 0.6, the latent heat flux derived from the Bowen ratio approach is shown to be greater than that derived from the nonparametric approach. When the Bowen ratio is greater than 0.8 , the nonparametric approach-based latent heat flux is continuously larger than the estimates based on the Bowen ratio approach. For the sensible heat flux, the results are completely opposite. When the Bowen ratio is equal to 0.6 , the estimates from both approaches are nearly equal. The difference between the two approaches is about $100 \mathrm{~W} / \mathrm{m}^{2}$ for the Bowen ratio with 10 . Through the two types of simulations above, the results indicates that the nonparametric approach may greatly overestimate latent heat flux under dry conditions.

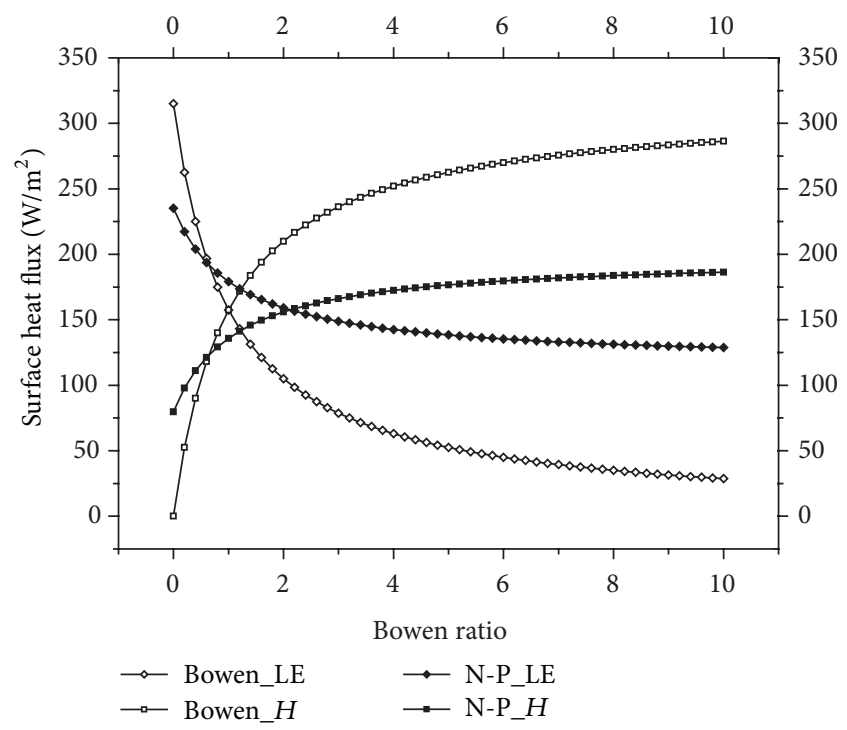

Figure 3: Comparison of latent heat flux and sensible heat flux derived from the Bowen ratio approach and the nonparametric approach.

TABLE 2: Quantitative computations of model performance with observations from three sites.

\begin{tabular}{lcccccc}
\hline Experiments & \multicolumn{2}{c}{ SMACEX } & \multicolumn{2}{c}{ WATER } & \multicolumn{2}{c}{ HAPEX-Sahel } \\
\hline \multirow{2}{*}{ Site name } & \multicolumn{2}{c}{ WC06 } & \multicolumn{2}{c}{ Yingke station } & \multicolumn{2}{c}{ Tiger Bush Site } \\
& LE & $H$ & LE & $H$ & LE & $H$ \\
\hline$N$ & 844 & 844 & 344 & 343 & 1441 & 1441 \\
MAD & 50.17 & 50.17 & 35.17 & 30.49 & 47.07 & 47.07 \\
RMSD & 58.26 & 58.26 & 51.11 & 42.45 & 67.54 & 67.54 \\
$E$ & 0.9 & -0.419 & 0.94 & 0.58 & -9.43 & 0.59 \\
Slope & 0.896 & 0.844 & 0.799 & 0.869 & 2.004 & 0.547 \\
Intercept & -30.46 & 49.17 & 10.41 & 21.54 & 30.64 & -9.352 \\
$R$-Square & 0.979 & 0.645 & 0.989 & 0.71 & 0.447 & 0.921 \\
\hline
\end{tabular}

4.2. Site Evaluation. In this section, the nonparametric approach was evaluated with site observations. The NashSutcliffe coefficient $(E)$ was used in this study to qualify the model performance. Nash-Sutcliffe coefficient ranges from -inf to 1 . Essentially, the closer to 1 it is, the more accurate the model is. Table 2 lists the statistical computations for the estimates based on the nonparametric approach at three different sites. Figure 4 presents the time series comparison of the surface heat fluxes estimated by the nonparametric approach with the measurements from the eddy covariance system at the WC06 site. The WC06 site, located in the central part of the United States, has a climate with a hot, wet summer. The estimates of the latent heat flux were found to have a good agreement with the observations at this site. The nonparametric approach shows a slightly underestimated latent heat flux. There were 844 samples in the comparison; the slope and the intercept of the linear regression between the two were 0.896 and $-30.46 \mathrm{~W} / \mathrm{m}^{2}$. The mean absolute deviation (MAD) and the root mean 

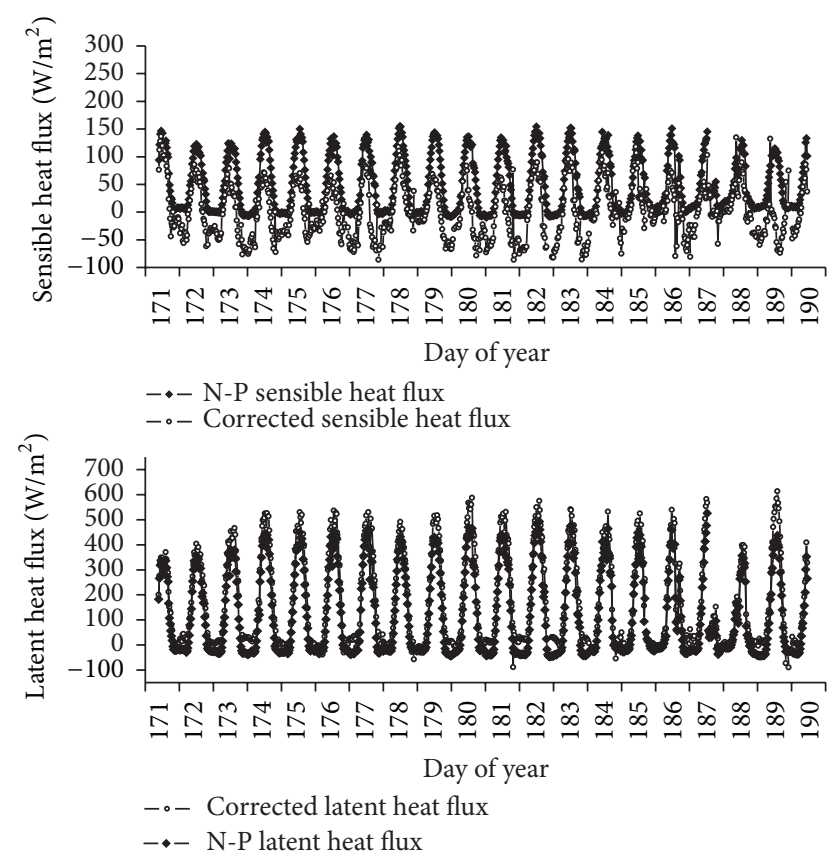

FIgURE 4: Time series comparison of the surface heat fluxes estimated by the nonparametric approach with the measurements from the eddy covariance system at the WC06 site. (The gap in the figure was due to lack of observations.)

square deviation (RMSD) were $50.17 \mathrm{~W} / \mathrm{m}^{2}$ and $58.26 \mathrm{~W} / \mathrm{m}^{2}$, respectively. The Nash-Sutcliffe coefficient $(E)$ was 0.9 . However, the approach seems to overestimate the sensible heat flux for about $60 \mathrm{~W} / \mathrm{m}^{2}$. The $E$ was -0.419 . The MAD and the RMSD were the same as those for the latent heat flux due to the complementary relationship with the sensible and latent heat fluxes. The corresponding slope and the intercept were 0.844 and $49.17 \mathrm{~W} / \mathrm{m}^{2}$.

A further evaluation was undertaken at the Yingke station. The Yingke station is located in the northwest part of China and the climate is dry year-round, with a hot summer and a cold winter. Figure 5 shows a comparison of the surface heat fluxes estimated by the nonparametric approach with the eddy covariance observations at this site. The results indicated that the nonparametric approach can effectively characterize the diurnal variations of the latent and sensible heat fluxes at this site. For the latent heat flux estimates, the slope and intercept of the regression line are 0.799 and $10.41 \mathrm{~W} / \mathrm{m}^{2}$. This comparison included 344 samples. The $E$ was 0.94 . The MAD and RMSD were $35.17 \mathrm{~W} / \mathrm{m}^{2}$ and $51.11 \mathrm{~W} / \mathrm{m}^{2}$, respectively. For the sensible heat flux estimates, the corresponding slope and the intercept were 0.869 and $21.54 \mathrm{~W} / \mathrm{m}^{2}$. The $E$ was 0.58 . The MAD and RMSD were $30.49 \mathrm{~W} / \mathrm{m}^{2}$ and $42.45 \mathrm{~W} / \mathrm{m}^{2}$, respectively.

The evaluations above were both carried out in cropland and the evaluations indicated that the nonparametric approach can provide a good estimate of latent heat flux for these conditions. In this part, a further evaluation was undertaken at the Tiger Bush Site, which is covered by bare soil and has a hot and dry climate year-round. Figure 6
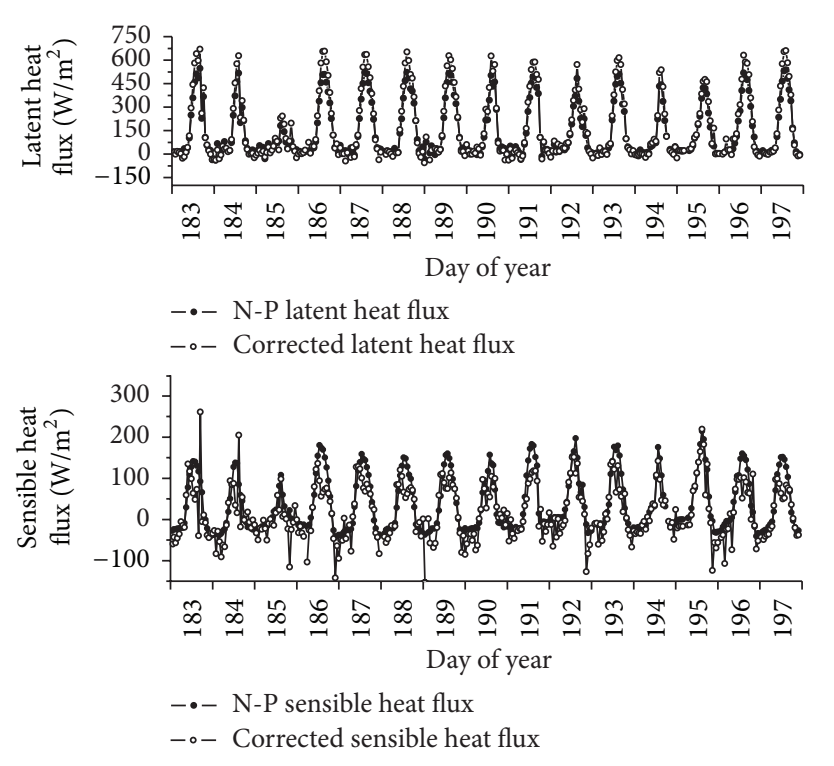

FIgURE 5: Comparison of the surface heat fluxes estimated by the nonparametric approach with the measurements from the eddy covariance system at Yingke site.

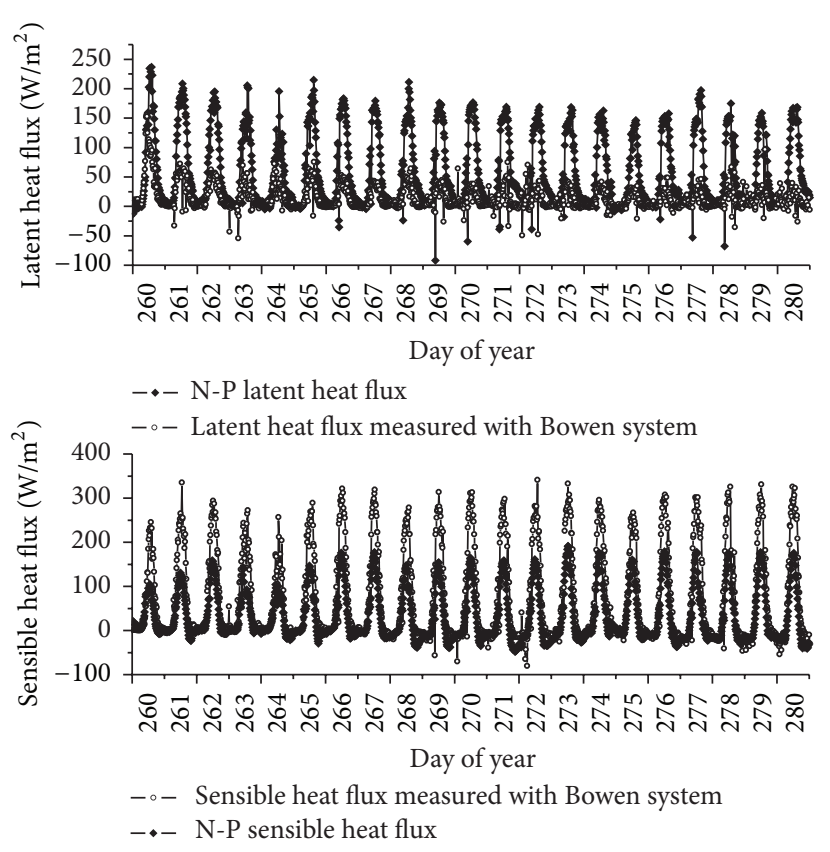

Figure 6: Comparison of the surface heat fluxes estimated by the nonparametric approach with the measurements from the Bowen system at the Tiger Bush Site.

presents the time series comparison of the surface heat flux estimates and the observations at this site. It was found that the nonparametric approach would greatly overestimate the latent heat flux. The difference between the estimates and the observations can be as large as $130 \mathrm{~W} / \mathrm{m}^{2}$. On the contrary, the nonparametric approach greatly underestimated the sensible heat flux. The statistical computations were listed in Table 2. There were 1441 samples in the comparison. The MAD and 


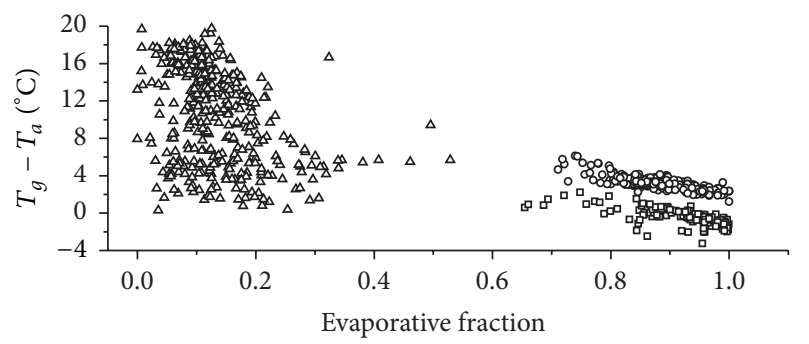

$\Delta$ Measurements from the Tiger Bush Site

- Measurements from the WC06 site

- Measurements from the Yingke site

(a)

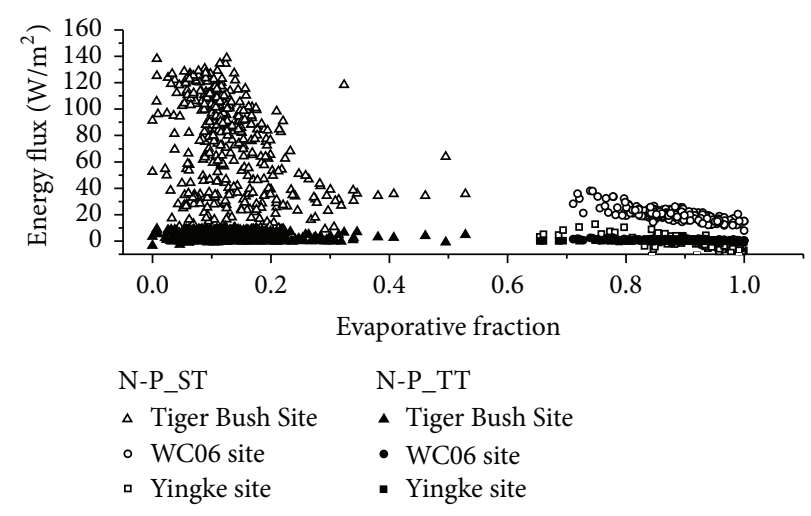

(b)

FIGURE 7: (a) Evaporative fraction versus $\left(T_{g}-T_{a}\right)$; (b) evaporative fraction versus two terms (N-P_ST and N-P_TT) of the nonparametric approach.

the RMSD were $47.07 \mathrm{~W} / \mathrm{m}^{2}$ and $67.54 \mathrm{~W} / \mathrm{m}^{2}$, respectively. For the LE estimates, the $E$ was -9.43 . The slope and the intercept of the fitted line were 2.0 and $30.64 \mathrm{~W} / \mathrm{m}^{2}$. For the sensible heat flux, the $E$ was 0.59 ; the slope and the intercept were 0.547 and $-9.35 \mathrm{~W} / \mathrm{m}^{2}$. The statistical computations quantitatively indicated that the nonparametric approach would greatly overestimate LE and underestimate $H$ at this site. The simulations in Section 4.1 compared the nonparametric approach with the Penman-Monteith equation and the Bowen ratio approach. The results demonstrated that the nonparametric approach has greater estimates than the Penman-Monteith equation and the Bowen ratio approach under dry conditions. The evaluation at the Tiger Bush Site further confirmed that this approach would greatly overestimate the latent heat flux under dry conditions.

4.3. Comparison between the Equilibrium Evaporation and the Nonparametric Approach. Sections 4.1 and 4.2 evaluated the nonparametric approach with a model simulation and site observations. The results firmly indicated that the nonparametric approach would greatly overestimate ET under dry conditions. Liu et al. [18] evaluated this approach with observations collected from 26 eddy covariance sites and they found an absolute difference of $10.3 \pm 20.2$ (mean \pm standard deviation) $\mathrm{W} / \mathrm{m}^{2}$ for latent heat flux. In this study, we also found this approach to provide promising LE estimates for two crop sites, namely, Yingke and WC06 station. Soil moisture may be one of the most important factors that influence the performance of this approach. In this section, the nonparametric approach will be further analyzed. The evaporative fraction, the ratio between LE and available energy $\left(R_{n}-G\right)$, is a good indicator of water availability for evaporation and will be used in the following analysis. To eliminate uneven measurements at night time, the observations between 10:00 and 16:00 (in local time) from all three sites were selected. The difference between ground surface temperature and air temperature $\left(T_{g}-T_{a}\right)$, evaporative fraction, and the three terms $\left(E_{\text {eq }}\right.$, N-P_ST, and $\mathrm{N}-\mathrm{P} \_\mathrm{TT}$ ) of the nonparametric approach were computed for every measurement record. Figure 7 shows the scatter plot of evaporative fraction versus $\left(T_{g}-T_{a}\right)$ and evaporative fraction versus two terms of the nonparametric approach. There are generally three point clusters in Figure 7(a), which correspond to the measurements from the three sites. For the Tiger Bush Site, the evaporative fraction is smaller than 0.4, and most points located in the range of $0-0.3$, indicating low soil moisture availability for evaporation. For the other two sites, the evaporative fraction is greater than 0.65 , which indicates ample water for evaporation. $\left(T_{g}-T_{a}\right)$ is quiet large in the Tiger Bush Site with small evaporative fraction values, while it shows small values (lower than $4^{\circ} \mathrm{C}$ ) at the Yingke and the WC06 sites with large evaporative fraction values. Figure 7(b) shows N-P_ST and N-P_TT with varying evaporative fraction values. It was found that N-P_ST shows similar point clusters as that in Figure 7(a). For the Tiger Bush Site, N-P_ST ranged from 20 to $140 \mathrm{~W} / \mathrm{m}^{2}$. For the Yingke and WC06 sites, N-P_ST was generally smaller than $40 \mathrm{~W} / \mathrm{m}^{2}$. N-P_TT, the third term in (9), is smaller than $15 \mathrm{~W} / \mathrm{m}^{2}$ at all three sites. This indicates that this term has little function in the nonparametric approach. From the analysis above, it is found that N-P_TT and N-P_ST have relatively small values for wet conditions with high evaporative fraction values. In addition, N-P_TT and N-P_ST have the different signs in (9). This may imply that the nonparametric approach is very close to the equilibrium evaporation equation under wet conditions. The results shown in Figure 8 support this deduction. For the Yingke and WC06 sites, the difference between the estimates from nonparametric approach and the estimates from the equilibrium evaporation was relatively small. However, the difference is relatively large at the Tiger Bush Site which has small evaporative fraction values. Figure 8 provides two other differences, namely, the difference between the estimates from the nonparametric approach and the site observations, as well as the difference between the estimates from the equilibrium evaporation and the site observations. Figure 9 provides the comparison between observed latent heat fluxes with the estimates from the equilibrium evaporation. For the measurements from the Yingke and WC06 sites, most of 


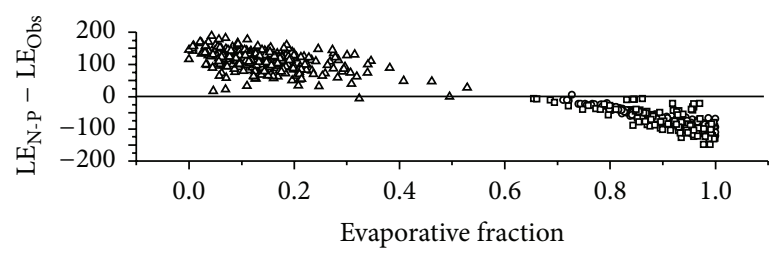

(a)

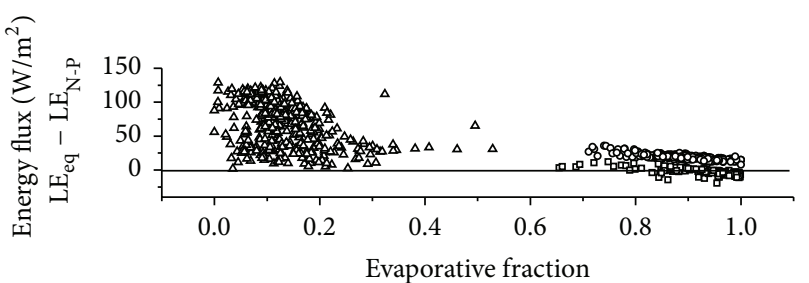

(b)

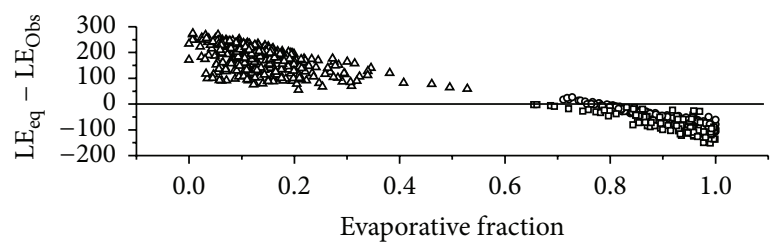

$\triangle$ Tiger Bush Site

- WC06 site

- Yingke site

(c)

FiguRE 8: (a) The difference between the estimates from the nonparametric approach and the site observations; (b) the difference between the estimates from the nonparametric approach and the estimates from the equilibrium evaporation; (c) the difference between the estimates from the equilibrium evaporation and the site observations.

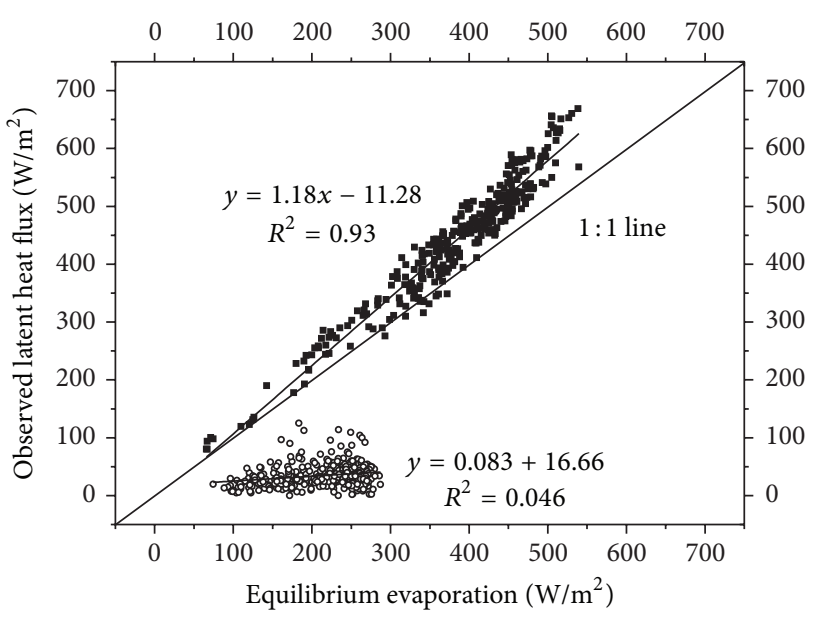

- Measurements from the Yingke and WC06 site

- Measurements from the Tiger Bush Stie

FIGURE 9: Estimates from the equilibrium evaporation versus the sites observations.

the points were close to the 1:1 line; the slope and the intercept of the fitted line were 1.18 and $-11.28 \mathrm{~W} / \mathrm{m}^{2}$. This indicated that the equilibrium evaporation is a good approximate for the latent heat flux for the Yingke and WC06 sites with high evaporative fraction values. However, this does not hold for the Tiger Bush Site, which has relatively small evaporative fraction values. The slope and the intercept of the fitted line were 0.083 and $16.66 \mathrm{~W} / \mathrm{m}^{2}$. This corresponded to the study by Denmead and McIlroy [32], who suggested that the equilibrium evaporation might be closely approximate to the actual crop evaporation.

\section{Discussion}

Actual ET estimation has long been a difficult problem for hydrometeorologists. The nonparametric approach proposed by Liu et al. [18] is attractive, because the solution is simple and without parameterization of a transfer coefficient. In our study, the nonparametric approach was evaluated using both model simulation and site observations. The simulation indicated that this approach would greatly overestimate ET under dry conditions. It is worthwhile to note that the simulation analysis may present two minor problems. First, the aerodynamic surface temperature and the ground surface temperature are not equal; this has already been reported by many researchers $[29,30]$. However, the difference is not significant over dense cropland. Secondly, the soil heat flux in the simulation analysis was used as a constant value in comparison with the Bowen ratio approach. This may not be realistic in real conditions. The overestimation of the nonparametric approach under dry conditions indicated by the simulation analysis was quite clear, and this was further confirmed by the Tiger Bush Site observations in Section 4.2.

The site evaluations indicated that the nonparametric approach could provide promising estimates for the Yingke and WC06 sites, but it would fail for the Tiger Bush Site, which was relatively dry. Liu et al. [18] evaluated the nonparametric approach with observations from 26 sites and found that this approach worked well at most sites. In 3 of 26 sites, they found that the performance of the nonparametric approach was relatively poor (see Table 2 in their paper). In the analysis of the reason for the bad performance for three sites, they pointed out that these sites had no common features in climate conditions. In this study, both model simulation and in situ evaluation at the Tiger Bush Site reveal that the nonparametric approach would greatly overestimate 
ET under dry conditions. In addition, Liu et al. [18] pointed out that the performance of the nonparametric approach is comparable to the Penman-Monteith approach and the Bowen ratio approach with 2 site observations. However, the evaluation at the Tiger Bush Site (actual ET observed with the Bowen approach) in this study does not support this statement.

Every term in the nonparametric approach was further analyzed in Section 4.3. It was found that the nonparametric approach is very close to the equilibrium evaporation equation at the Yingke and WC06 sites, as the second term and the third term are relatively small and have different signs to offset each other. However, this is not the case for the Tiger Bush Site, as the actual ET is mainly controlled by limited soil moisture under dry circumstances. In fact, Denmead and McIlroy [32] have suggested that the equilibrium evaporation may serve as a simple measure for actual ET. This suggestion is further supported by many field experiments $[3,33,34]$. A clearer description of this problem can be found in the book by Monteith [20], as cropland usually has moderate surface resistance, and the equilibrium evaporation would be a close approximation of the actual crop evaporation. The scatter plot in Figure 9 also provides a solid support. This may be an implication of the good performance of the nonparametric approach at the 23 sites in Liu's paper and 2 sites in this paper. The application of the nonparametric approach needs more caution under dry conditions. In addition, it is worthwhile to point out that the deviation of the nonparametric approach needs more thorough investigation, for the third term in the equation has little function.

Soil moisture plays an important role in drylands ecosystems [35]. In drylands, soil moisture plays a dominant role in hydrological processes. Drylands cover more than 40 percent of Earth's land surface and are inhabited by nearly 40 percent of the world's population [36]. However, there have still been insufficient observation sites in sparsely vegetated areas. Further research on the drylands hydrological process is imperative.

\section{Conclusion}

In this study, a critical evaluation of the nonparametric approach was undertaken. Both the model simulation and the site evaluation at Tiger Bush Site indicated that this approach would greatly overestimate ET under dry conditions. However, two crop site evaluations have shown that this approach can achieve good performance. Further analysis revealed that the nonparametric approach is very close to the equilibrium evaporation equation, which approaches the actual ET under wet conditions. In addition, it has been found that the third term has little influence on the results. The evaluations indicate that the application of this approach needs to be cautious and avoided in dry conditions.

\section{Conflict of Interests}

The authors declare no conflict of interests.

\section{Authors' Contribution}

Yongmin Yang proposed and developed the research design, paper writing, and results interpretation. Hongbo Su supervised all the work that has been done by the first author and revised the paper extensively. Jianwei Qi did part of the data analysis and revised the paper.

\section{Acknowledgments}

The authors are very thankful to the researchers in SMACEX, WATER, and HAPEX-Sahel for the data acquisition and sharing. This work is supported jointly by the Project of National Natural Science Foundation of China (41171286) and the High Resolution Earth Observation System Program of China (no. 08-Y30B07-9001-13/15).

\section{References}

[1] C. Folke, S. Carpenter, T. Elmqvist, L. Gunderson, C. S. Holling, and B. Walker, "Resilience and sustainable development: building adaptive capacity in a world of transformations," Ambio, vol. 31, no. 5, pp. 437-440, 2002.

[2] J. G. Liu, T. Dietz, S. R. Carpenter et al., "Complexity of coupled human and natural systems," Science, vol. 317, no. 5844, pp. 15131516, 2007.

[3] W. Brutsaert, Evaporation into the Atmosphere: Theory, History, and Applications, Springer, New York, NY, USA, 1982.

[4] D. M. Lawrence, P. E. Thornton, K. W. Oleson, and G. B. Bonan, "The partitioning of evapotranspiration into transpiration, soil evaporation, and canopy evaporation in a GCM: impacts on land-atmosphere interaction," Journal of Hydrometeorology, vol. 8, no. 4, pp. 862-880, 2007.

[5] W. Brutsaert, Hydrology: An Introduction, Cambridge University Press, 2005.

[6] C. H. Priestley and R. J. Taylor, "On the assessment of surface heat flux and evaporation using large-scale parameters," Monthly Weather Review, vol. 100, no. 2, pp. 81-92, 1972.

[7] W. J. Shuttleworth, "Putting the 'vap' into evaporation," Hydrology and Earth System Sciences, vol. 11, no. 1, pp. 210-244, 2007.

[8] J. Dalton, "Experimental essays on the constitution of mixedgases. On evaporation and the expansion of gases by heat," Memoirs and Proceedings of the Manchester Literary \& Philosophical Society, vol. 5, pp. 535-602, 1802.

[9] A. Fick, "Ueber diffusion," Annalen der Physik und Chemie, vol. 170, no. 1, pp. 59-86, 1855.

[10] I. S. Bowen, "The ratio of heat losses by conduction and by evaporation from any water surface," Physical Review, vol. 27, no. 6, pp. 779-787, 1926.

[11] H. L. Penman, "Natural evaporation from open water, bare soil and grass," Proceedings of the Royal Society of London Series A: Mathematical, Physical and Engineering Sciences, vol. 193, no. 1032, pp. 120-145, 1948.

[12] J. L. Monteith, "Evaporation and environment," in The State and Movement of Water in Living Organisms, Proceedings of the 19th Symposia of the Society for Experimental Biology, Swansea, UK, Cambrige Unversity Press, 1965.

[13] R. G. Allen, L. Pereira, D. Raes, and M. Smith, FAO Irrigation and Drainage Paper No. 56. Crop Evapotranspiration (Guidelines for Computing Crop Water Requirements), FAO, Rome, Italy, 1998. 
[14] F. I. Morton, "Evaporation research-a critical review and its lessons for the environmental sciences," Critical Reviews in Environmental Science and Technology, vol. 24, no. 3, pp. 237280, 1994.

[15] K. C. Wang and R. E. Dickinson, "A review of global terrestrial evapotranspiration: observation, modeling, climatology, and climatic variability," Reviews of Geophysics, vol. 50, no. 2, 2012.

[16] K. Yang, M. Rasmy, S. Rauniyar et al., "Initial CEOP-based review of the prediction skill of operational general circulation models and land surface models," Journal of the Meteorological Society of Japan, vol. 85, pp. 99-116, 2007.

[17] M. R. Raupach, "Influences of local feedbacks on land-air exchanges of energy and carbon," Global Change Biology, vol. 4, no. 5, pp. 477-494, 1998.

[18] Y. B. Liu, T. Hiyama, T. Yasunari, and H. Tanaka, "A nonparametric approach to estimating terrestrial evaporation: validation in eddy covariance sites," Agricultural and Forest Meteorology, vol. 157, pp. 49-59, 2012.

[19] B. D. Tanner, "Use requirements for Bowen ratio and eddy correlation determination of evapotranspiration," in Planning Now for Irrigation and Drainage in the 21st Century, R. DeLynnHay, Ed., p. 782, ASCE, 1988.

[20] J. L. Monteith, Vegetation and the Atmosphere, Volume 1 Principles, Academic Press, New York, NY, USA, 1975.

[21] W. P. Kustas, J. L. Hatfield, and J. H. Prueger, “The soil moistureatmosphere coupling experiment (SMACEX): background, hydrometeorological conditions, and preliminary findings," Journal of Hydrometeorology, vol. 6, no. 6, pp. 791-804, 2005.

[22] X. Li, Z. Li, M. Ma et al., "Watershed allied telemetry experimental research," Journal of Geophysical Research D: Atmospheres, vol. 114, no. 22, Article ID D22103, 2009.

[23] J. P. Goutorbe and J. P. Goutorbe, "Hapex-Sahel - a LargeScale Study of Land-Atmosphere Interactions in the Semiarid Tropics," Annales Geophysicae-Atmospheres Hydrospheres and Space Sciences, vol. 12, no. 1, pp. 53-64, 1994.

[24] H. Su, M. F. McCabe, E. F. Wood, Z. Su, and J. H. Prueger, "Modeling evapotranspiration during SMACEX: comparing two approaches for local- and regional-scale prediction," Journal of Hydrometeorology, vol. 6, no. 6, pp. 910-922, 2005.

[25] T. E. Twine, W. P. Kustas, J. M. Norman et al., "Correcting eddycovariance flux underestimates over a grassland," Agricultural and Forest Meteorology, vol. 103, no. 3, pp. 279-300, 2000.

[26] K. Yang and J. M. Wang, "A temperature prediction-correction method for estimating surface soil heat flux from soil temperature and moisture data," Science in China, Series D: Earth Sciences, vol. 51, no. 5, pp. 721-729, 2008.

[27] Y. Song, J. Wang, K. Yang et al., "A revised surface resistance parameterisation for estimating latent heat flux from remotely sensed data," International Journal of Applied Earth Observation and Geoinformation, vol. 17, no. 1, pp. 76-84, 2012.

[28] J. S. Wallace and C. J. Holwill, "Soil evaporation from tiger-bush in south-west Niger," Journal of Hydrology, vol. 188-189, no. 1-4, pp. 426-442, 1997.

[29] W. P. Kustas, B. J. Choudhury, M. S. Moran et al., "Determination of sensible heat flux over sparse canopy using thermal infrared data," Agricultural and Forest Meteorology, vol. 44, no. 3-4, pp. 197-216, 1989.

[30] J. B. Stewart, W. P. Kustas, K. S. Humes, W. D. Nichols, M. S. Moran, and H. A. de Bruin, "Sensible heat flux-radiometric surface temperature relationship for eight semiarid areas," Journal of Applied Meteorology, vol. 33, no. 9, pp. 1110-1117, 1994.
[31] R. Zhang, X. Sun, Z. Zhu, H. Su, and X. Tang, "A remote sensing model for monitoring soil evaporation based on differential thermal inertia and its validation," Science in China, Series D: Earth Sciences, vol. 46, no. 4, pp. 342-355, 2003.

[32] O. T. Denmead and I. C. Mcllroy, "Measurements of nonpotential evaporation from wheat," Agricultural Meteorology, vol. 7, no. 4, pp. 285-302, 1970.

[33] J. A. Davies, "Actual, potential and equilibrium evaporation for a beanfield in southern Ontario," Agricultural Meteorology, vol. 10, no. 4-5, pp. 331-348, 1972.

[34] R. G. Wilson and W. R. Rouse, "Moisture and temperature limits of the equilibrium evapotranspiration model," Journal of Applied Meteorology, vol. 11, no. 3, pp. 436-442, 1972.

[35] L. Wang, P. D'Odorico, J. P. Evans et al., "Dryland ecohydrology and climate change: critical issues and technical advances," Hydrology and Earth System Sciences, vol. 16, no. 8, pp. 25852603, 2012.

[36] UNEP, World Atlas of Desertification, United Nations Environment Programme (UNEP), Nairobi, Kenya, 1992. 

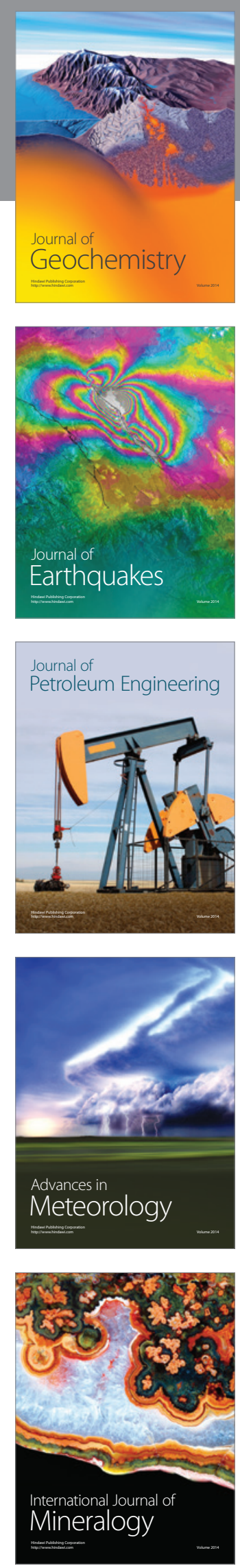
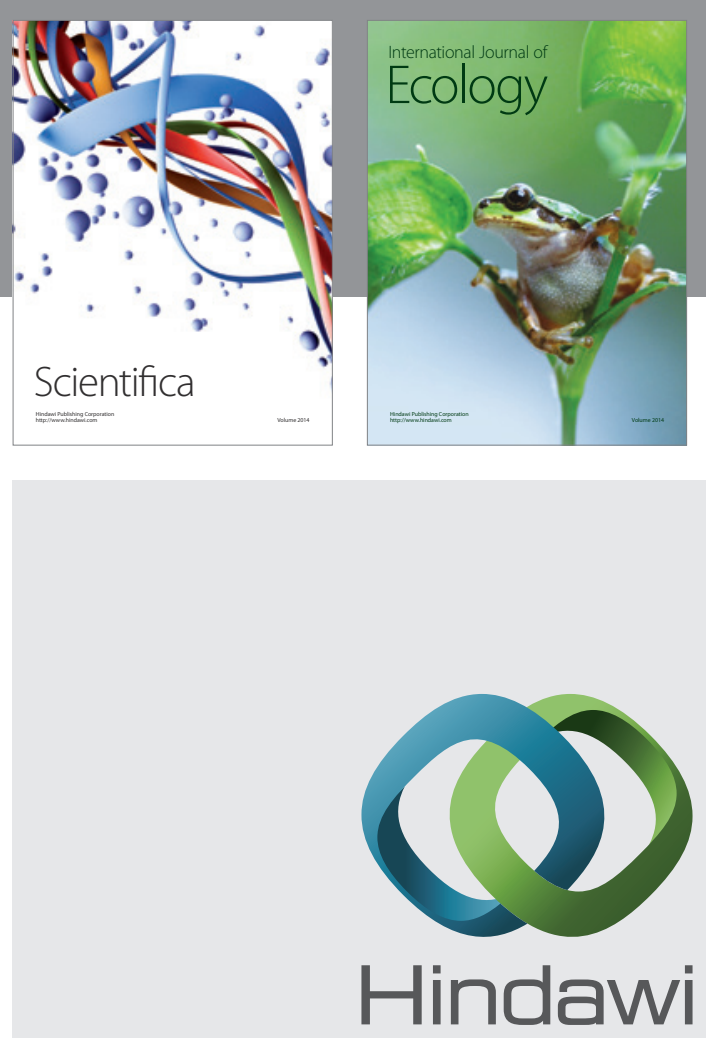

Submit your manuscripts at

http://www.hindawi.com
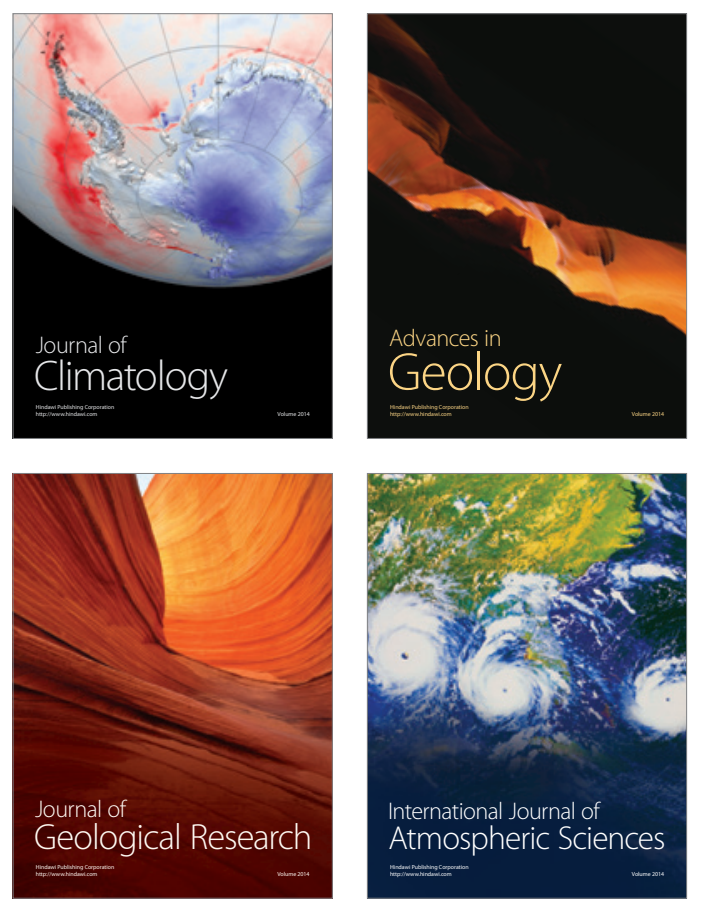

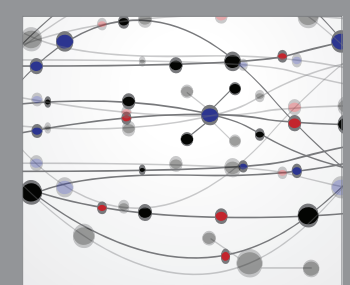

The Scientific

\section{World Journal}
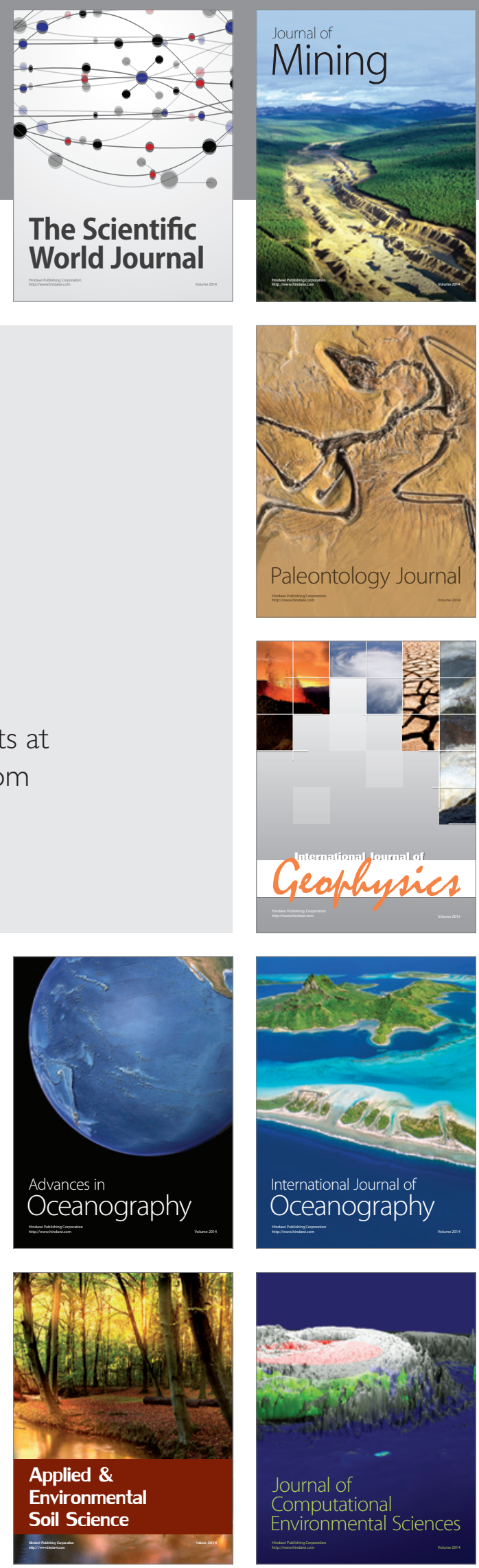